Microscopy Coming Events

2015

Frontiers in Light Microscopy Symposium November 17, 2015

National Institutes of Health, Bethesda, MD

https://ncifrederick.cancer.gov/events/

LightMicroscopy

2015 MRS Fall Meeting \& Exhibition

November 29-December 4, 2015

Boston, MA

Sponsor: Materials Research Society (MRS)

www.mrs.org/fall2015

American Society for Cell Biology (ASCB)

2015 Annual Meeting

December 12-16, 2015

San Diego, CA

http://ascb.org/future-ascb-annual-meetings

2016

Physics and Chemistry of Semiconductor

Surfaces and Interfaces (PCSI-43)

January 17-21, 2016

Location: Palm Springs, CA

www.pcsiconference.org

24th Australian Conference on

Microscopy and Microanalysis

January 31-February 4, 2016

Melbourne, Australia

www.acmm2016.org

Nanoscience and Nanotechnology (ICONN) 2016

February 7-11, 2016

Canberra, Australia

www.ausnano.net/iconn2016

60th Annual Meeting, Biophysical Society

February 27-March 2, 2016

Los Angeles, CA

www.biophysics.org/Meetings/AnnualMeeting/

tabid/85/Default.aspx

PITTCON Conference

March 6-10, 2016

Atlanta, GA

http://pittcon.org

2016 MRS Spring Meeting

March 28-April 1, 2016

Phoenix, AZ

www.mrs.org/spring2016

Microscopy \& Microanalysis 2016

July 24-28, 2016

Columbus, $\mathrm{OH}$

www.microscopy.org

\section{7}

Microscopy \& Microanalysis 2017

July 23-27, 2017

St. Louis, MO

www.microscopy.org

2018

Microscopy \& Microanalysis 2018

August 5-9, 2018

Baltimore, MD

www.microscopy.org

2019

Microscopy \& Microanalysis 2019

August 4-8, 2019

Portland, OR

www.microscopy.org

2020

Microscopy \& Microanalysis 2020

August 2-6, 2020

Milwaukee, WI

www.microscopy.org

More Meetings and Courses

Check the complete calendar near the

back of this magazine.

\title{
Scanning Electron Microscopy Shows How to Keep Cool in the Desert
}

\author{
Stephen W. Carmichael \\ Mayo Clinic, Rochester, MN 55905 \\ carmichael.stephen@mayo.edu
}

The silver ants of the Sahara desert, Cataglyphis bombycina, inhabit a unique ecological niche where their diet consists mainly of the bodies of insects and other arthropods that cannot survive in the heat as well as they can. Recently, Norman Nan Shi, Cheng-Chia Tsai, Fernando Camino, Gary Bernard, Nanfang Yu, and Rüdiger Wehner showed that the secret to the ants' survival is the shape of the hairs that cover much (but not all!) of their bodies.

In addition to thermodynamic measurements, full-wave simulations, and heat-transfer modeling, Shi et al. used scanning electron microscopy to examine the hairs that cover only the top and the sides of the ant's body. They found a dense array of parallel hairs that were triangular in cross section. Interestingly, the two surfaces facing outwards were corrugated, whereas the surface facing the ant's body was flat. The array of hairs was structured so that they reflected visible and near-infrared radiation through phenomena known as Mie scattering and total internal reflection. The hair-covered region reflected $67 \%$ of the incoming solar radiation rather than only $41 \%$, as was the case after the hair was removed from the cuticle. There were variations in the hairs' cross-sectional areas, but it was determined that resonance peaks from individual hairs were averaged out so that the hair cover effectively acts as a coating with enhanced broadband reflection in the solar radiation spectrum.

Shi et al. compared reflective properties of triangular and circular hairs of the same cross-sectional area. Even though the reflectance was similar when the incoming solar radiation was normal to the hair-coated surface, triangular hairs produced an extra enhancement of reflectivity at oblique angles of incidence. This is because

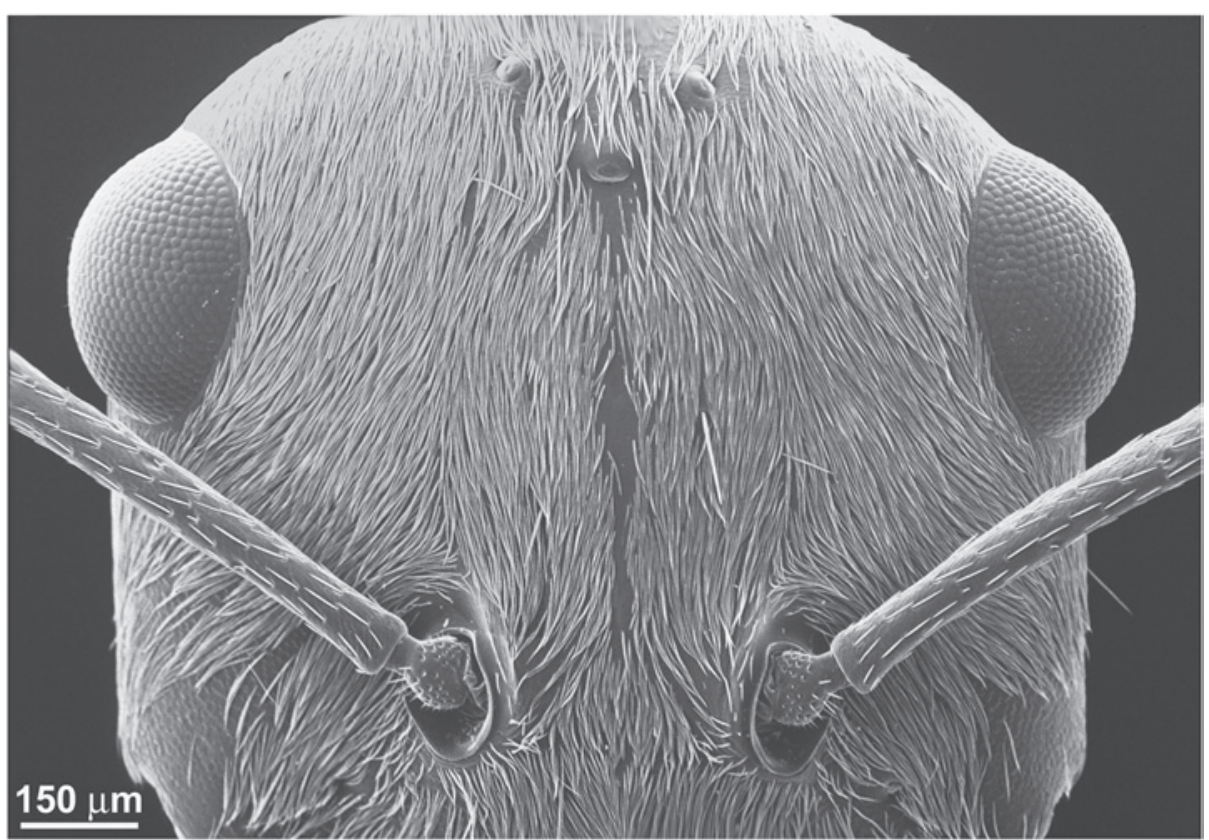

Figure 1: Scanning electron micrograph of the head of a Saharan silver ant. 


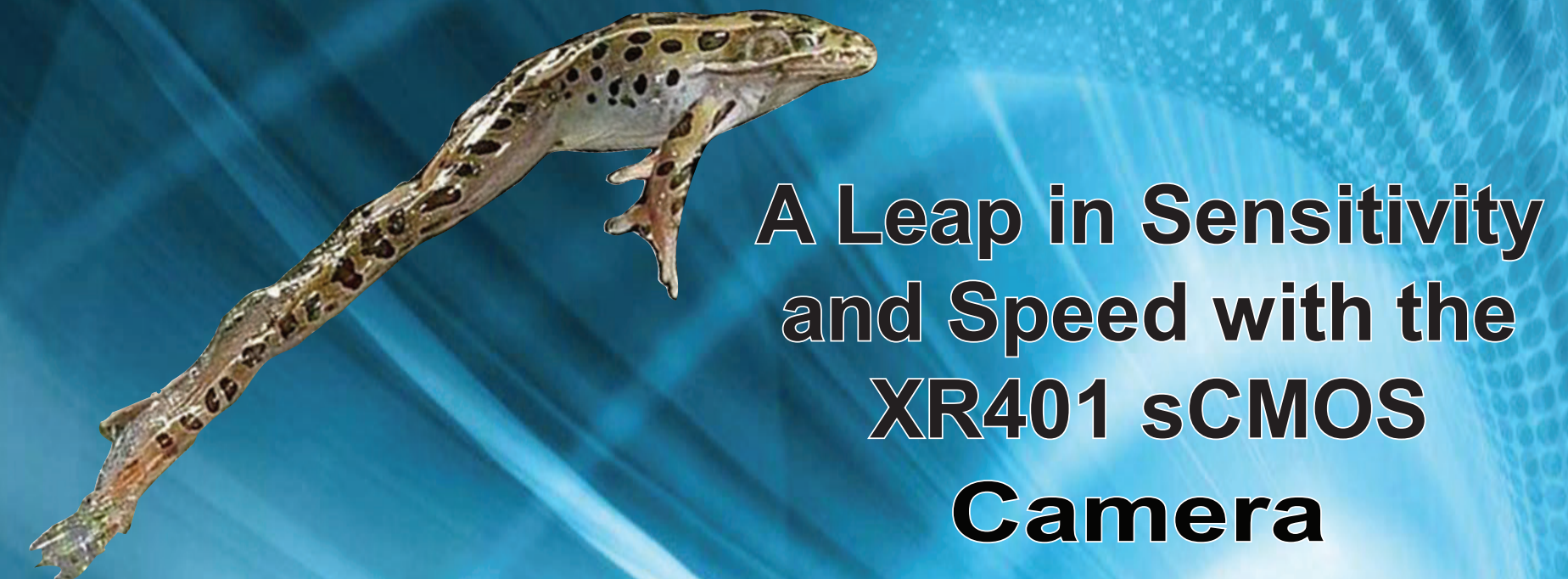

- Diffraction
- In-Situ TEM
- Extraordinary speed

- Non-Blooming Sensor - $<2$ e/pixel noise

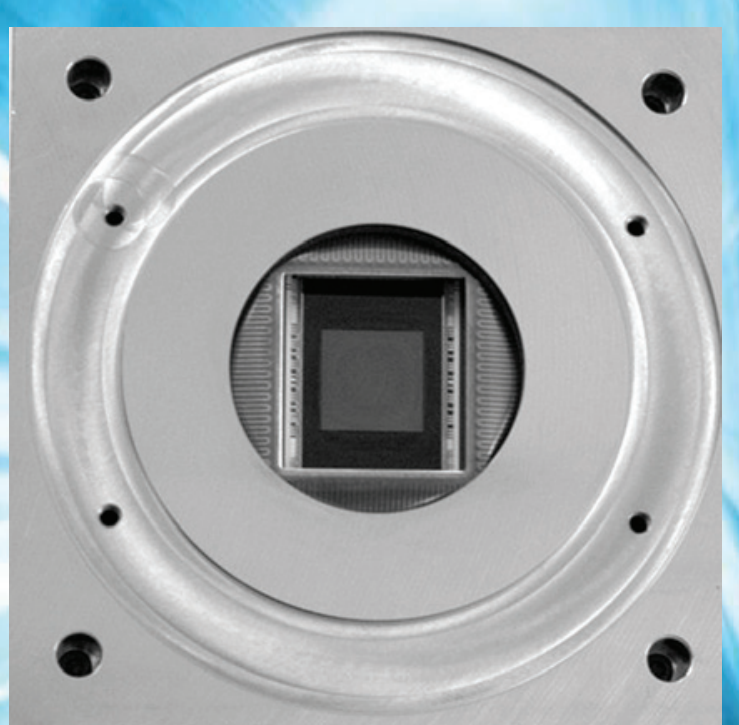

Adenovirus

Dr. Cameron Ackerley

The Hospital for Sick Children

\section{A Leap in Sensitivity and Speed with the XR401 sCMOS}

\section{Camera}

\section{Cryo TEM}

- Low Dose TEM
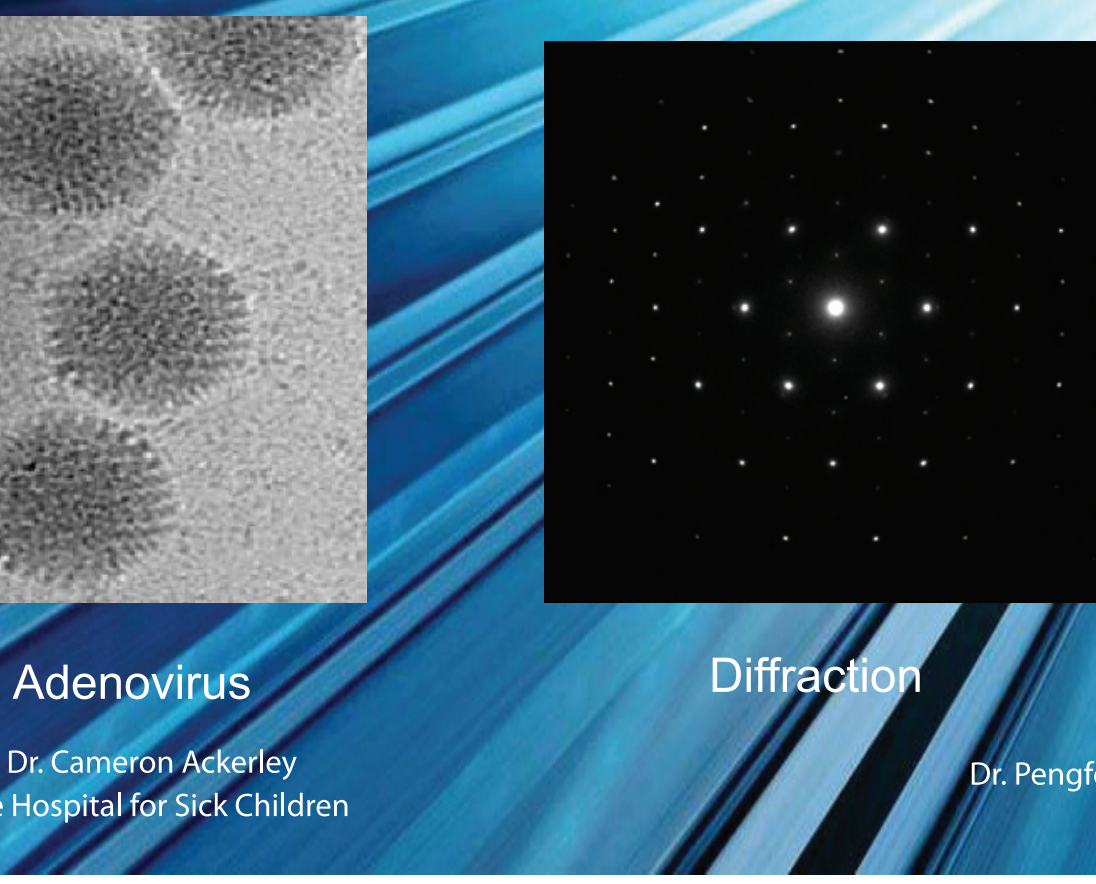

242 West Cummings Park, Woburn, MA 01801

Phone: 978.774.5550 www.amtimaging.com

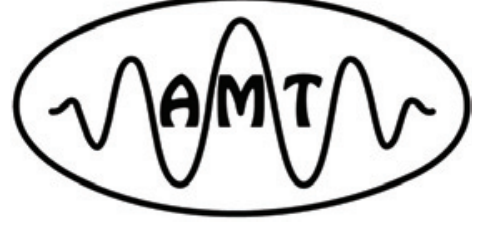


Mie scattering of similar strength occurs in both circular and triangular hairs; in the latter the total internal reflection from the bottom flat surfaces of individual hairs substantially enhances reflectivity.

An equally important function of the hair array in the thermoregulation of the ants is that it enhances emission of heat radiation from the ant's body. Shi et al. showed this in a series of thermodynamic experiments where the efficiencies in dissipating heat as thermal radiation are compared between ants with intact hair covers and with bald surfaces. Furthermore, the hairless bottom surface of the ant was shown to reduce the radiative energy transfer between the hot sand and the cooler ant body so that the animals can reduce the absorption of blackbody radiation from desert floor. This occurs in the mid-infrared range.

The most exciting aspect of these studies is the demonstration that properties of a structured surface, specifically the shape and surface characteristics of hair-like projections, can provide effective passive cooling of objects. This biological solution for a thermoregulatory problem could lead to the development of biomimetic coatings that would be very beneficial!

\section{References}

[1] N Shi et al., Science 349 (2015) 298-301.

[2] The author gratefully acknowledges Dr. Nanfang Yu for reviewing this article.

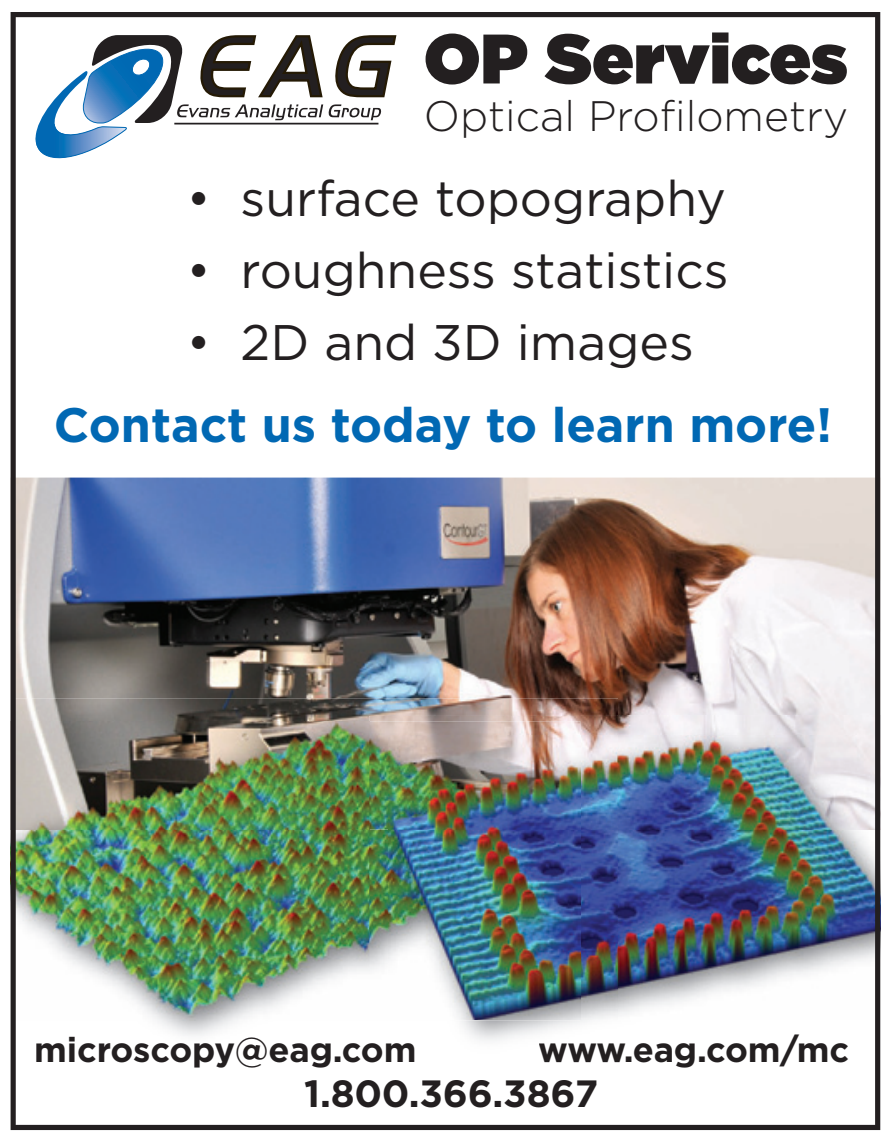

\section{(20) tousimis}
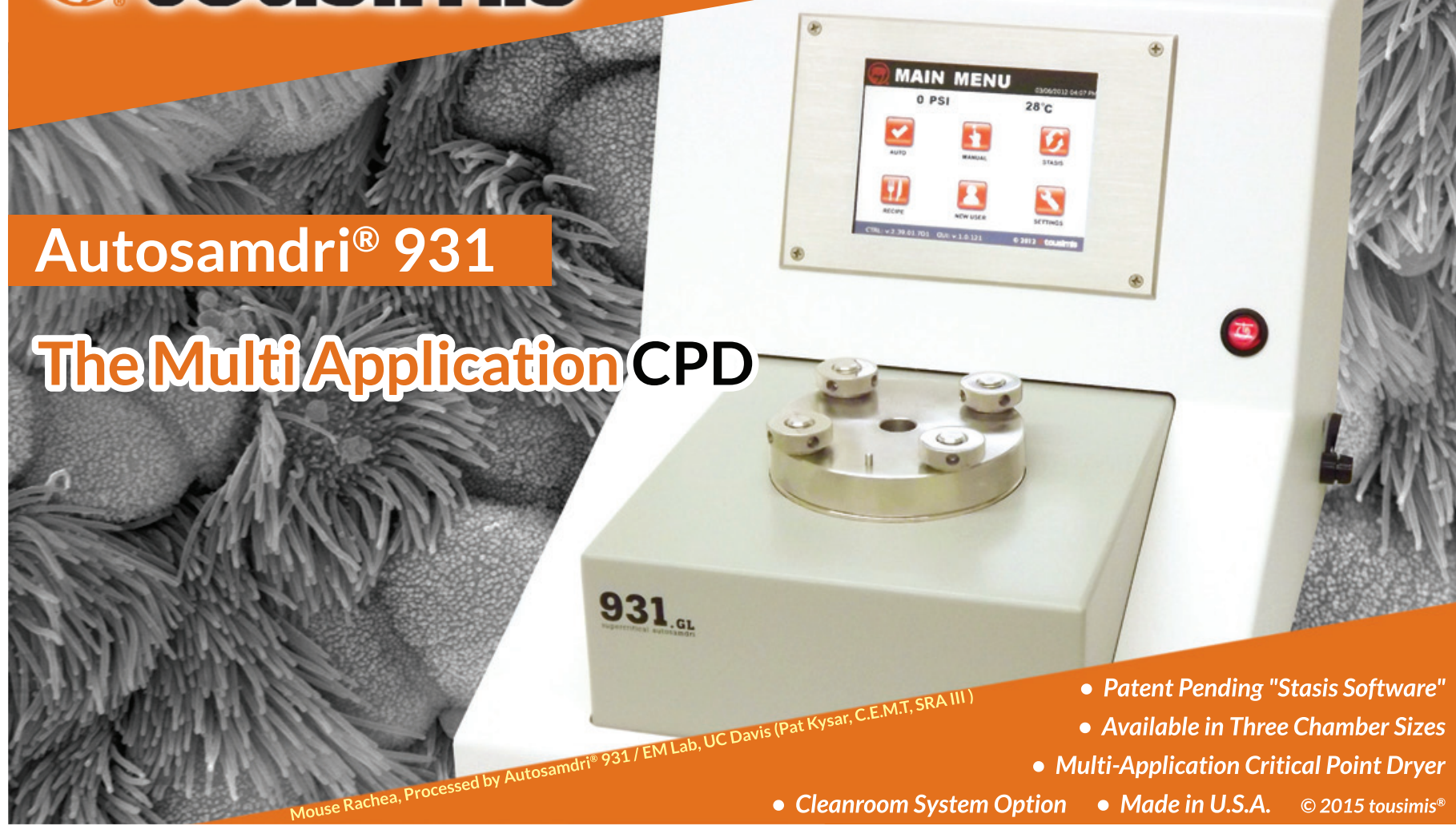


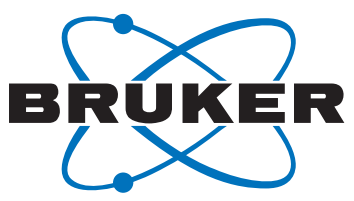

\section{Techniques - 1 Workflow.}

ESPRIT 2, the

only software

which combines

4 microanalysis methods.
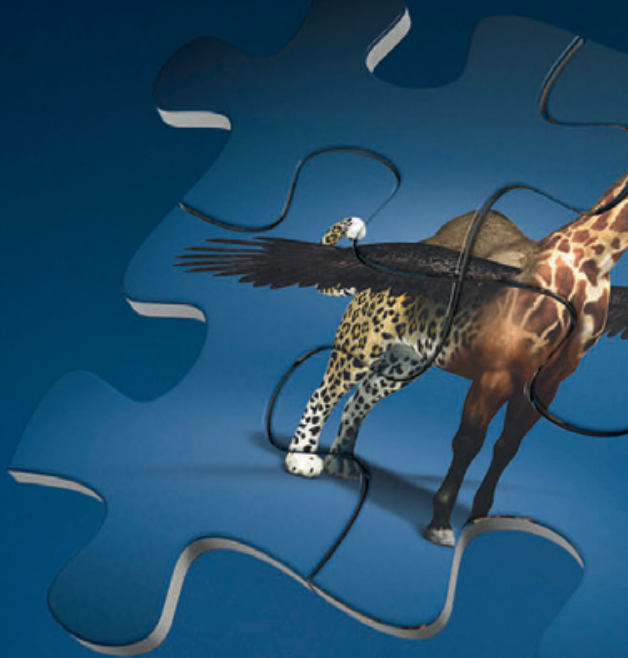

(1)
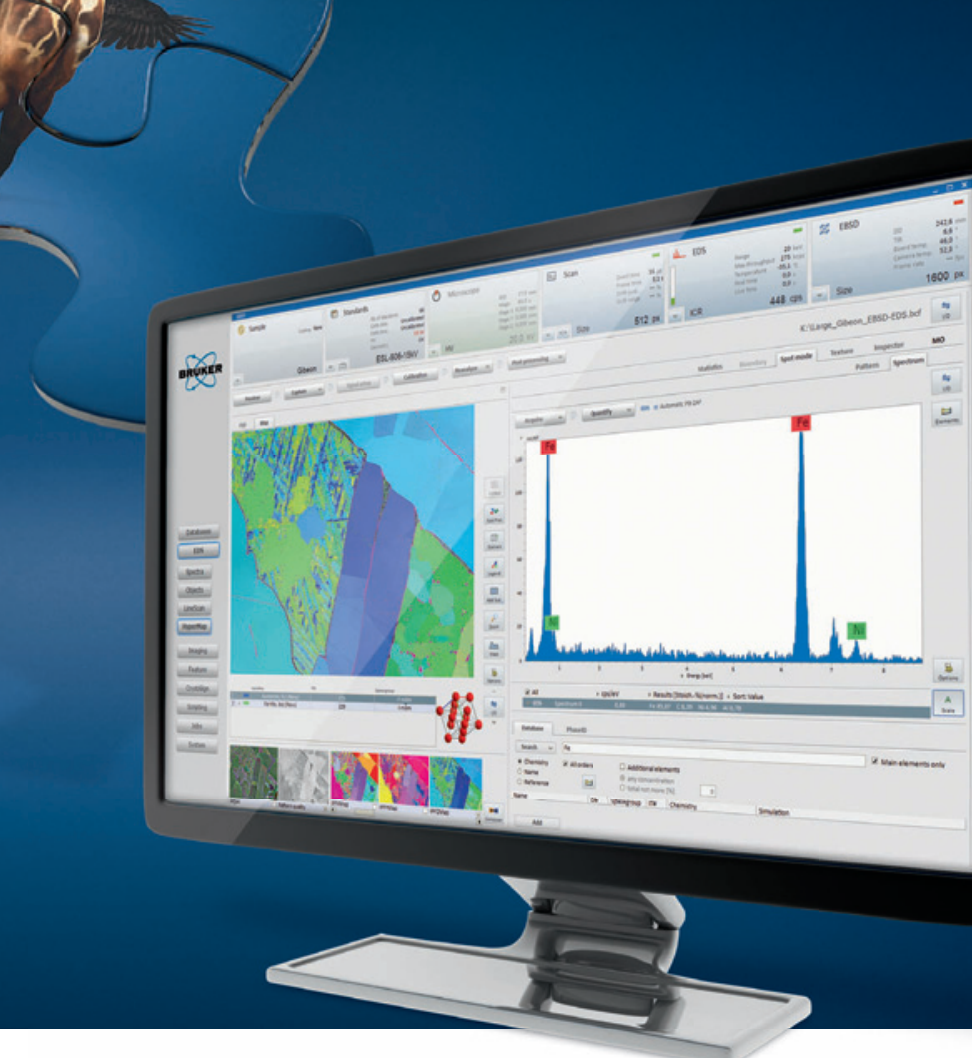

- Comprehensive management of analysis and results from EDS, WDS, EBSD and Micro-XRF with one software

- Complementary techniques provide you the most accurate and reliable results

- Zeta factor quantification for characterization of thin layers

Someone has to be first.

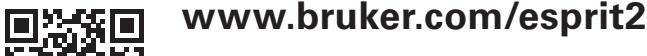

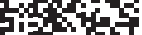

trits

asty

Innovation with Integrity 